\title{
Review Article \\ GPCRs: Lipid-Dependent Membrane Receptors That Act as Drug Targets
}

\author{
Amitabha Chattopadhyay \\ CSIR-Centre for Cellular and Molecular Biology, Uppal Road, Hyderabad 500 007, India \\ Correspondence should be addressed to Amitabha Chattopadhyay; amit@ccmb.res.in
}

Received 20 July 2014; Accepted 6 September 2014; Published 2 October 2014

Academic Editor: Luis Loura

Copyright ( 2014 Amitabha Chattopadhyay. This is an open access article distributed under the Creative Commons Attribution License, which permits unrestricted use, distribution, and reproduction in any medium, provided the original work is properly cited.

G protein-coupled receptors (GPCRs) are the largest class of molecules involved in signal transduction across cell membranes and represent major targets in the development of novel drug candidates in all clinical areas. Although there have been some recent leads, structural information on GPCRs is relatively rare due to the difficulty associated with crystallization. A specific reason for this is the intrinsic flexibility displayed by GPCRs, which is necessary for their functional diversity. Since GPCRs are integral membrane proteins, interaction of membrane lipids with them constitutes an important area of research in GPCR biology. In particular, membrane cholesterol has been reported to have a modulatory role in the function of a number of GPCRs. The role of membrane cholesterol in GPCR function is discussed with specific example of the serotonin ${ }_{1 \mathrm{~A}}$ receptor. Recent results show that GPCRs are characterized with structural motifs that preferentially associate with cholesterol. An emerging and important concept is oligomerization of GPCRs and its role in GPCR function and signaling. The role of membrane cholesterol in GPCR oligomerization is highlighted. Future research in GPCR biology would offer novel insight in basic biology and provide new avenues for drug discovery.

\section{G Protein-Coupled Receptors as Cellular Nanomachines}

The G protein-coupled receptor (GPCR) superfamily comprises the largest and most diverse group of proteins in mammals and is involved in information transfer (signal transduction) from outside the cell to the cellular interior [1-4]. GPCRs are typically seven transmembrane domain proteins (see Figure 1) and include $>800$ members which are encoded by $\sim 5 \%$ of human genes [5]. Evolutionary data reveal that GPCRs and G protein signaling dates back $~ 1.2$ billion years, prior to plants, fungi, and animals emerging from a common ancestor [6]. GPCRs in mammals are classified into five main families, named Glutamate, Rhodopsin, Adhesion, Frizzled, and Secretin according to the GRAFS classification $[7,8]$. Each of these families is characterized by long evolutionary history.

Cellular signaling by GPCRs involves their activation by ligands present in the extracellular environment, and the subsequent signal transduction to the interior of the cell through concerted changes in their transmembrane domain structure [9]. GPCRs regulate physiological responses to a variety of stimuli that include endogenous ligands such as biogenic amines, peptides, glycoproteins, lipids, nucleotides, $\mathrm{Ca}^{2+}$ ions, and various exogenous ligands for sensory perception such as odorants, pheromones, and even photons. As a consequence, these receptors mediate multiple physiological processes such as neurotransmission, cellular metabolism, secretion, cellular differentiation, growth, inflammatory, and immune responses. For this reason, GPCRs have emerged as major targets for the development of novel drug candidates in all clinical areas [10-13]. It is estimated that $~ 50 \%$ of clinically prescribed drugs and 25 of the 100 top selling drugs target GPCRs $[14,15]$. Yet, only a small fraction of all GPCRs are presently targeted by drugs [16]. This points out the exciting possibility that the receptors which are not recognized yet could be potential drug targets for diseases that are difficult to treat by currently available drugs. Importantly, the Nobel Prize in Chemistry in 2012 was awarded to Brian Kobilka and Robert Lefkowitz for their pioneering studies on GPCRs [17]. 


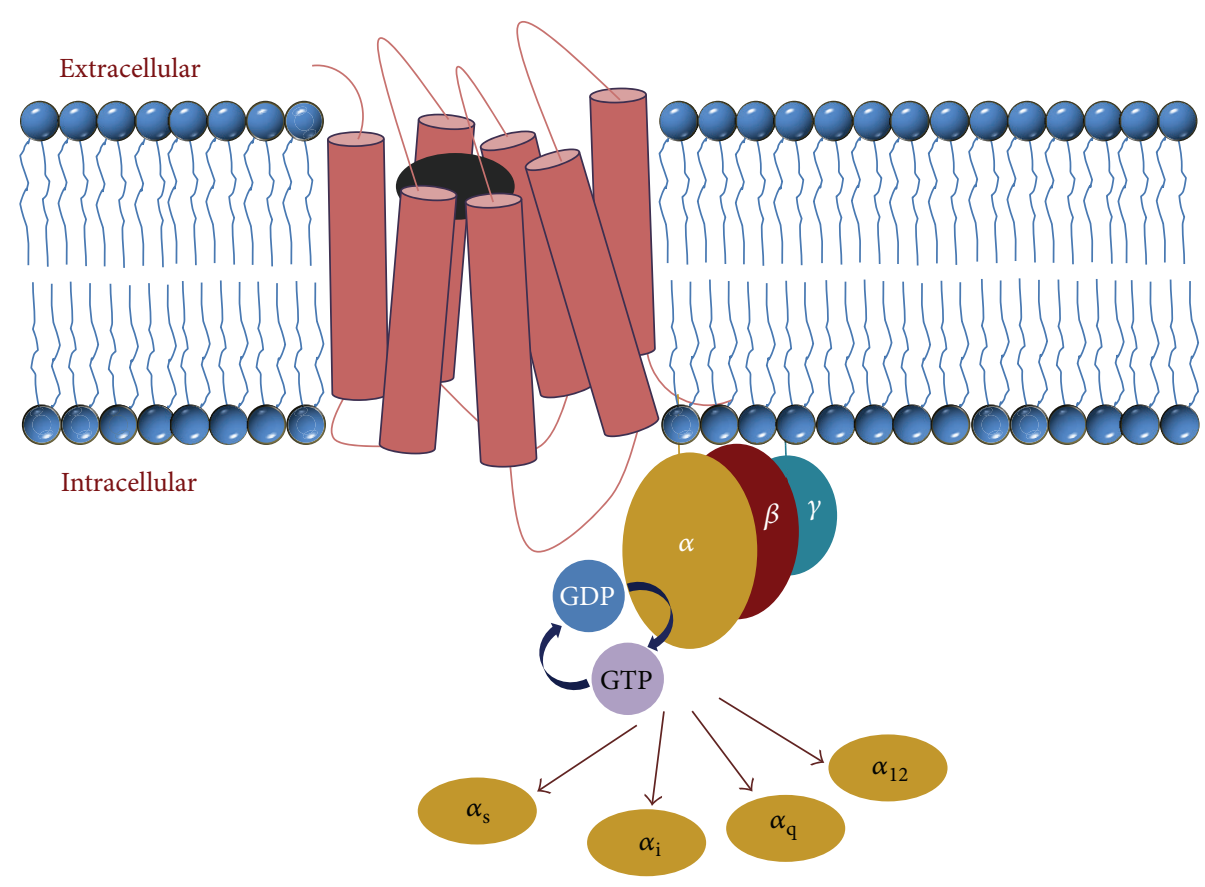

FIGURE 1: A schematic representation of G protein-coupled receptor (GPCR) and its signaling. GPCRs are integral membrane proteins with seven transmembrane domains. A consequence of having odd number of transmembrane passes is that the amino and carboxy terminals are localized on opposite sides of the cellular membrane. The helices are often tilted resulting in compact structure due to helix-helix interaction and packing. GPCRs are activated by a wide variety of ligands that include biogenic amines, amino acids, ions, lipids, peptides, and various exogenous ligands such as odorants, pheromones, and even photons. Although the ligand shown here (in black) binds at the transmembrane region of the receptor, there are ligands that bind at the extracellular region of the receptor, depending on the receptor type. Upon binding to specific ligands, GPCRs activate heterotrimeric G proteins (consisting of $\alpha, \beta$, and $\gamma$ subunits). Activated G proteins regulate diverse signaling cascades, depending on their subtype $\left(\alpha_{\mathrm{s}}, \alpha_{\mathrm{i}}, \alpha_{\mathrm{q}}\right.$, and $\alpha_{12}$ families). As a consequence, these receptors mediate multiple physiological processes such as neurotransmission, cellular metabolism, secretion, cellular differentiation, growth, inflammatory, and immune responses. See text for more details.

\section{Structural Biology of GPCRs: Why Is It So Difficult?}

In general, crystallization efforts of membrane proteins in their native conditions are often complicated and pose considerable challenge. This is due to the intrinsic dependence of membrane protein structure on surrounding membrane lipids and the limited extramembrane portion of the protein available for crystal contacts [18]. Although the first complete $\mathrm{X}$-ray crystallographic analysis of an integral membrane protein was carried out a number of years back [19], the number of membrane proteins whose X-ray crystal structures are known is still very small and represents a small fraction (less than 1\%) of all solved protein structures. Even among membrane proteins, crystallizing GPCRs poses considerable challenge. The reason for this lies in the remarkable structural plasticity displayed by GPCRs which is necessary for the functional diversity exhibited by GPCRs. The functional diversity of GPCRs is difficult to explain by a simple binary (on/off) switch model of receptor activation and is better explained by dynamic and adaptable structures [20]. Rather than functioning as toggle switches that can turn preselected linear signaling cascades on or off, GPCRs act as signaling hubs that can regulate alternative subsets of signaling modes, depending on the receptor conformations stabilized by specific ligands [21]. Data from a number of laboratories have shown that GPCRs are characterized by flexible and dynamic structures and various ligands stabilize specific receptor conformations. In this context, the term "ligand" could also include membrane lipids which have been shown to stabilize GPCRs in specific conformations [22-24]. The structural plasticity displayed by GPCRs therefore provides the platform for diverse signaling pathways in response to specific ligands and also forms the basis for the difficulty in obtaining crystal structures of GPCRs. The conformational dynamics of GPCRs is beginning to be appreciated in relation to their function $[25,26]$.

A useful way to visualize the structural plasticity and activation of GPCRs is through energy landscapes [20, 25]. The energy landscape provides information on protein dynamics leading to activation. Protein dynamics could span a range and could vary between local (small-scale) dynamics to relatively large-scale dynamics of protein helices. When viewed from this perspective, GPCRs represent an ensemble of conformations, each of which is characterized with a distinct energy level. Usually, X-ray crystallography is capable of capturing relatively stable conformations (structures). It should be noted here that although these represent more stable 
conformations, other conformations are equally important for understanding GPCR activation and function. A particularly attractive feature of structure determination by NMR is that it reports dynamic features and is capable of capturing less stable conformations [26, 27].

It is for this reason that most of the early GPCR structures reported by $\mathrm{X}$-ray crystallography represent inactive states stabilized by ligands such as inverse agonists [28, 29]. As mentioned above, the inherent conformational instability (flexibility) poses a problem for X-ray crystallography. This was taken care of by stabilizing the flexible regions of GPCRs (e.g., the third intracellular loop) using monoclonal antibody [30]. Alternatively, the third intracellular loop was replaced with lysozyme for stabilizing the helices (V and VI) that connect the loop with the rest of the protein $[28,31]$. A more recent approach to stabilize GPCRs in an active conformation is by heterotrimeric $G$ proteins [32]. Although the number of reported crystal structures of GPCRs is on the rise [33], the challenge that remains is to understand how ligand binding to GPCRs is converted into a series of conformational changes leading to receptor activation and signaling. Interestingly, the structure of CXCR1 receptor in membrane bilayers has recently been reported using NMR spectroscopy without any alteration to the protein structure [34].

\section{Lipid Specificity of GPCRs}

GPCRs are integral membrane proteins with multiple transmembrane passes. The interaction of membrane lipids with these receptors is therefore an important determinant in their structure and function [36, 41-44]. In addition, it has recently been reported that the interaction between GPCRs and $G$ proteins could be modulated by membrane lipids [45]. Importantly, the membrane lipid environment of GPCRs has been implicated in disease progression during aging [46]. Early indications on the importance of the membrane lipid environment for optimal functioning of GPCRs were evident from the adverse effects of delipidation on the function of the $\beta$-adrenergic receptor [47]. The membrane lipid which has been most studied in the context of GPCR-lipid interaction is cholesterol.

3.1. Cholesterol: A Lipid Intimately Associated with GPCRs. Cholesterol is an important and representative membrane lipid in higher eukaryotes. Cholesterol plays a crucial role in membrane organization, dynamics, function, and sorting $[48,49]$. Membrane cholesterol is often found to be distributed in a nonrandom fashion in domains (or pools) in biological and model membranes [50-53]. These domains are envisaged to be crucial since various cellular processes such as membrane sorting and trafficking [54], signal transduction [55], and the entry of pathogens [56-58] have been attributed to these types of domains. As mentioned earlier, the role of cholesterol in the function and organization of membrane proteins and receptors constitutes an emerging and exciting area of research [36, 41-44]. Yet, the detailed mechanism underlying the effect of membrane cholesterol on the structure and function of membrane proteins and receptors is not clear and appears to be complex $[43,59,60]$. A possible mechanism by which membrane cholesterol has been proposed to modulate the function of membrane proteins is by a direct (specific) interaction, which could induce a conformational change in the receptor. A second possibility proposes an indirect way by altering the membrane physical properties in which the protein is embedded. Another possibility could be a combination of both.

A particular kind of proposed specific interaction is based on the concept of "nonannular" binding sites of membrane lipids in membrane proteins [60,61]. Nonannular sites are characterized by lack of accessibility to the annular lipids; that is, these sites cannot be displaced by competition with annular lipids [62, 63]. We earlier proposed that cholesterol binding sites in GPCRs could represent nonannular binding sites whose possible locations could be inter- or intramolecular (interhelical) protein interfaces [61]. Integral membrane proteins are surrounded by a shell (or annulus) of lipid molecules denoted as "annular" lipids [64]. The rate of exchange of lipids between the annular lipid shell and the bulk lipid phase was shown to be approximately an order of magnitude slower than the rate of exchange of bulk lipids [43, 64]. In addition, it has been previously proposed that the cholesterol binding sites for $\mathrm{Ca}^{2+} / \mathrm{Mg}^{2+}$-ATPase $[62,65]$ and the nicotinic acetylcholine receptor [63] could be "nonannular" in nature. This was apparent from the analysis of fluorescence quenching of intrinsic tryptophans of membrane proteins by brominated phospholipids or cholesterol $[62,63]$. The exchange of lipid molecules between nonannular sites and bulk lipids is proposed to be relatively slow compared to the exchange between annular sites and bulk lipids although this has not yet been shown experimentally. Binding to the nonannular sites is considered to be more specific compared to annular binding sites $[43,61,64]$.

Membrane cholesterol has been shown to modulate the function of a number of GPCRs [35, 36, 41-44, 66-74]. A specific GPCR that has received a lot of attention in terms of cholesterol sensitivity of its organization, dynamics, and function is the serotonin sA $_{1 \mathrm{~A}}$ receptor [36, 42, 43]. The serotonin iA $_{1 \mathrm{~A}}$ receptor is an important neurotransmitter receptor and is implicated in the generation and modulation of various cognitive, behavioral, and developmental functions [75-77]. The agonists [78] and antagonists [79] of this receptor represent major classes of molecules with potential therapeutic applications in anxiety- or stress-related disorders. As a result, the serotonin ${ }_{1 \mathrm{~A}}$ receptor serves as an important drug target for neuropsychiatric disorders such as anxiety and depression [80].

Seminal work from our laboratory showed that membrane cholesterol plays a crucial role in the organization, dynamics, and function of the serotonin $_{1 \mathrm{~A}}$ receptor (reviewed in $[36,42,43])$. This was demonstrated utilizing a variety of approaches which include (i) physical depletion of membrane cholesterol using the sterol-specific carriers such as methyl$\beta$-cyclodextrin (M $\beta \mathrm{CD}$ ) $[66,68]$, (ii) treatment with agents such as nystatin (a polyene antibiotic) [67] and digitonin (a saponin family detergent) [70], which complex cholesterol and modulate the availability of membrane cholesterol without physically depleting it, (iii) enzymatic oxidation of cholesterol to cholestenone by cholesterol oxidase [69], and 


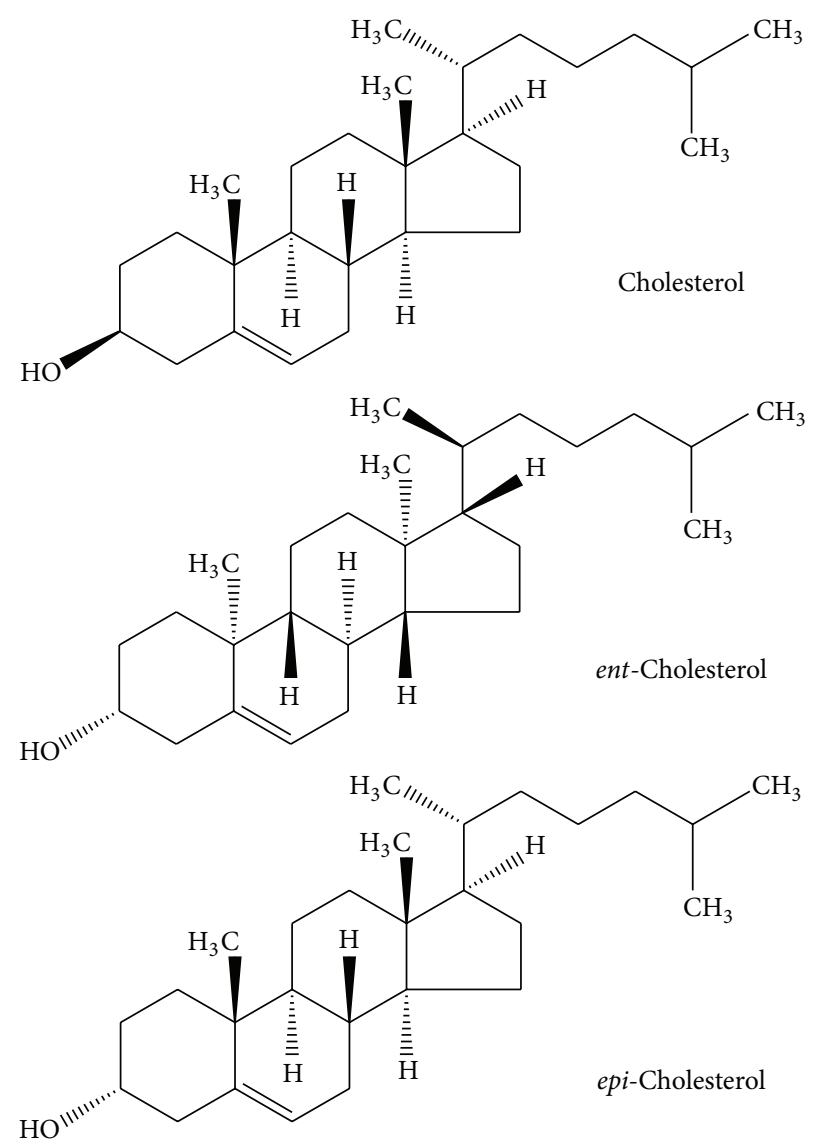

(a)

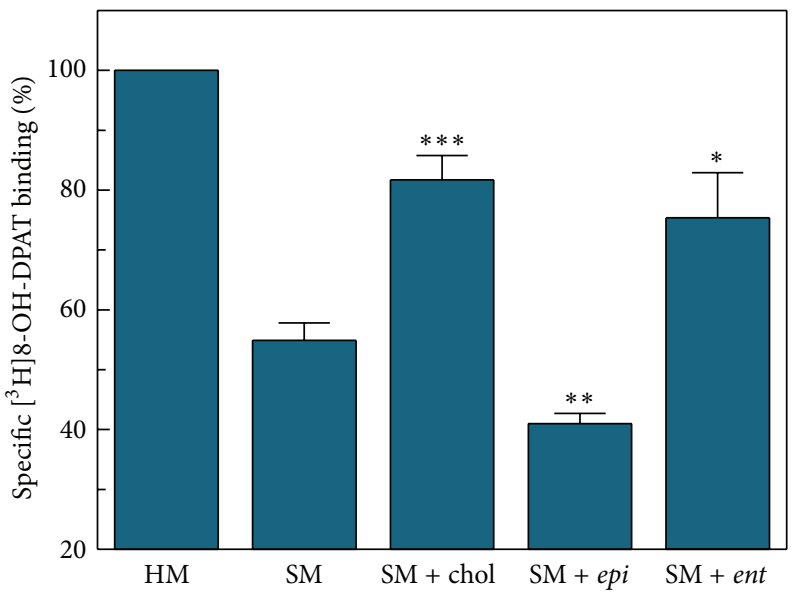

(b)

FIGURE 2: Stereospecific requirement of cholesterol in the function of the serotonin ${ }_{1 \mathrm{~A}}$ receptor. (a) Chemical structures of cholesterol and its stereoisomers: ent-cholesterol (enantiomer) and epi-cholesterol (diastereomer). ent-Cholesterol is a nonsuperimposable mirror image of cholesterol, whereas epi-cholesterol is not. (b) The effect of replenishment of cholesterol (chol), epi-cholesterol (epi), and ent-cholesterol (ent) into solubilized membranes (SM) on specific binding of the agonist $\left[{ }^{3} \mathrm{H}\right] 8-\mathrm{OH}-\mathrm{DPAT}$ to the serotonin $\mathrm{lA}_{1 \mathrm{~A}}$ receptor. Values are normalized to specific binding obtained in native hippocampal membranes (HM). The results show that the requirement of membrane cholesterol for the serotonin $_{1 \mathrm{~A}}$ receptor function is diastereospecific but not enantiospecific. Adapted and modified from [35]. See text for more details.

(iv) metabolic inhibition of cholesterol using biosynthetic inhibitors such as statin [72] and AY 9944 [71]. The common message emanated from these experiments was clear: nonavailability of membrane cholesterol, rather than the manner in which its availability is modulated, is crucial for receptor function. How specific is the requirement of cholesterol for receptor function? This was assessed by replacing cholesterol with its immediate biosynthetic precursors, 7dehydrocholesterol and desmosterol, both differing with cholesterol merely in an additional double bond. The fine stringency of cholesterol requirement for receptor function was apparent from the fact that these close biosynthetic precursors could not support receptor function [71, 81-83].

The degree of stringency was recently explored further by examining whether stereoisomers of cholesterol (entcholesterol and epi-cholesterol) could support receptor function. ent-Cholesterol is the enantiomer of cholesterol which is a nonsuperimposable mirror image of cholesterol. epiCholesterol, on the other hand, is a diastereomer and is not a mirror image of cholesterol. ent-Cholesterol, but not epi-cholesterol, shares identical physicochemical properties with cholesterol. Results showed that while ent-cholesterol could replace cholesterol in supporting the function of the serotonin $_{1 \mathrm{~A}}$ receptor, epi-cholesterol could not [35] (see Figure 2). In other words, the requirement of membrane cholesterol for the serotonin $n_{1 \mathrm{~A}}$ receptor function is diastereospecific, yet not enantiospecific. Interestingly, membrane cholesterol has been shown to be vital in improving serotonin $_{1 \mathrm{~A}}$ receptor stability under conditions of thermal deactivation, extreme $\mathrm{pH}$, and proteolytic digestion [24]. This is supported by receptor modeling studies which show that the serotonin $n_{1 \mathrm{~A}}$ receptor is more compact in the presence of tightly bound cholesterol [23] which could contribute to receptor stability [24]. Taken together, these results indicate that the molecular mechanism for the requirement of membrane cholesterol in maintaining the function of the

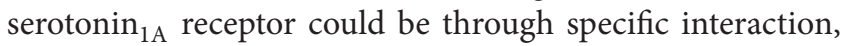
although global bilayer effects may not be completely ruled out [84]. 


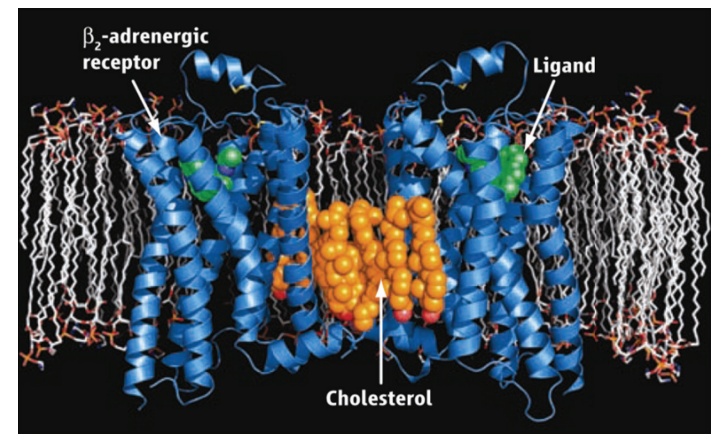

(a)

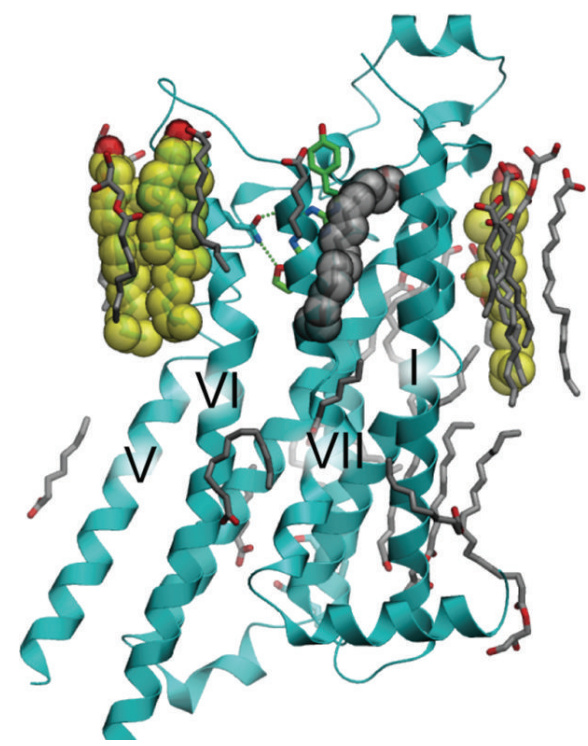

(c)

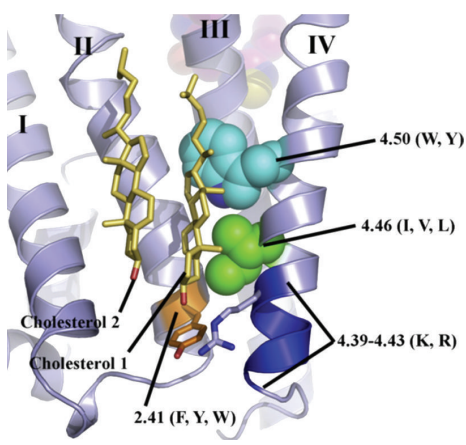

(b)

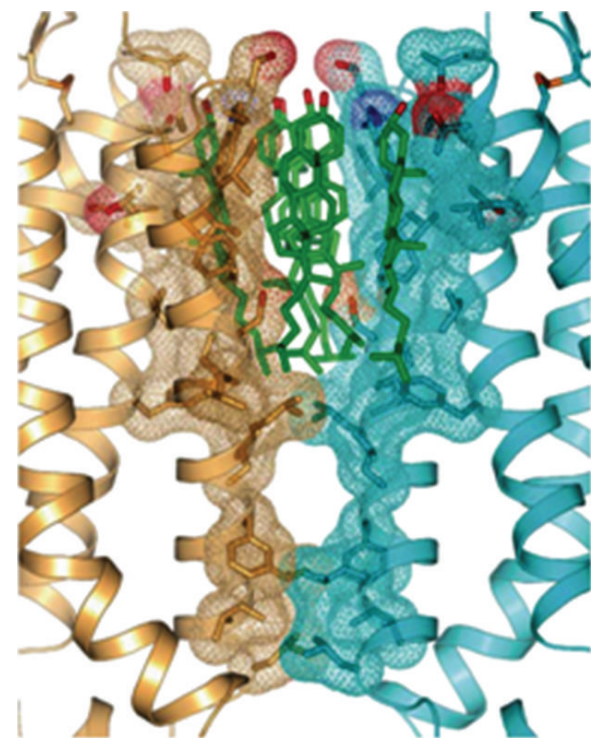

(d)

FIGURE 3: Crystal structures of GPCRs with closely associated cholesterol molecules. (a) The human $\beta_{2}$-adrenergic receptor structure (shown in blue) with bound carazolol (a partial inverse agonist; shown in green) embedded in a lipid bilayer. Cholesterol molecules between two receptor molecules are shown in orange. (b) The crystal structure of human $\beta_{2}$-adrenergic receptor (bound to the partial inverse agonist timolol) highlighting its cholesterol consensus motif (CCM). The side chain positions of the $\beta_{2}$-adrenergic receptor and two bound cholesterol molecules are shown. (c) The crystal structure of the human $\mathrm{A}_{2 \mathrm{~A}}$ adenosine receptor (in cyan) with three bound cholesterol molecules (yellow). ((a)-(c)) are reproduced from [36] with permission from Eureka Science Ltd. (d) depicts the dimer interface in the crystal structure of metabotropic glutamate type $1\left(\mathrm{mGlu}_{1}\right)$ receptor. Six bound cholesterol molecules (shown in green) are observed on the extracellular side of helices I and II of two monomers (shown in cyan and orange) of the mGlu 1 receptor involved in the dimer formation. Surface and stick presentations of the residues participating in receptor-cholesterol and receptor-receptor interactions are shown. Reproduced from [37], with permission from AAAS. See text for more details.

Membrane cholesterol has been shown to be important in improving the stability of the $\beta_{2}$-adrenergic receptor $[22,29]$ and appears to be necessary in the receptor crystallization [28]. Importantly, the $\beta_{2}$-adrenergic receptor enjoys $\sim 48 \%$ amino acid similarity with the serotonin ${ }_{1 \mathrm{~A}}$ receptor in the transmembrane region [23]. Such similarity in the transmembrane region could contribute to the cholesterol sensitivity in the function of the $\beta_{2}$-adrenergic receptor. In agreement with this, we recently showed that adrenergic signaling is enhanced upon cholesterol depletion in cardiac myocytes [73].

An important common feature observed in recently solved high resolution crystal structures of GPCRs (such as rhodopsin [85], $\beta_{1}$-adrenergic receptor [86], $\beta_{2}$-adrenergic receptor [28, 29], $\mathrm{A}_{2 \mathrm{~A}}$ adenosine receptor [87], and metabotropic glutamate type 1 receptor [37]) is the close association of cholesterol molecules to the receptor (see Figure 3). These recent crystal structures of GPCRs have enhanced our understanding of the role of membrane cholesterol in GPCR structure and function.

3.2. Cholesterol Binding Motifs in GPCRs. As mentioned above, an emerging feature in recently solved high resolution crystal structures of GPCRs is the presence of closely associated cholesterol molecules [28, 29, 37, 85-87] (Figure 3). Interestingly, several structural motifs of proteins and receptors have been postulated to induce preferential association with cholesterol $[43,88]$. These motifs include CRAC 
(cholesterol recognition/interaction amino acid consensus) motif [89, 90], CCM (cholesterol consensus motif) [29], SSD (sterol-sensing domain) [91, 92], and CARC (inverse CRAC) motif [93]. Out of these, the CRAC motif is characterized by the presence of the sequence $-\mathrm{L} / \mathrm{V}-(\mathrm{X})_{1-5}-\mathrm{Y}-(\mathrm{X})_{1-5}-\mathrm{R} / \mathrm{K}$ , in which $(\mathrm{X})_{1-5}$ represents between one and five residues of any amino acid [90]. We recently reported the presence of CRAC motifs in representative GPCRs such as rhodopsin, the $\beta_{2}$-adrenergic receptor, and the serotonin aA $_{\text {a }}$ receptor (see Figure 4) [38]. In addition, CRAC motifs have been reported in human type 1 cannabinoid receptor [94]. Importantly, all these receptors have been shown to exhibit membrane cholesterol sensitivity for their function. Long time scale MARTINI coarse-grain molecular dynamics simulations have recently validated high occupancy of cholesterol at some of the CRAC sites in the serotonin $_{1 \mathrm{~A}}$ receptor [39]. We have previously shown that CRAC motifs are inherent characteristic features of the serotonin ${ }_{1 \mathrm{~A}}$ receptor and are conserved over natural evolution [38]. Recently, an inverted CRAC domain (termed CARC) has been reported in which the CRAC sequence is oriented in the opposite direction along the polypeptide chain [93]. The CARC motif is present in several GPCRs and the nicotinic acetylcholine receptor and is found to be conserved over natural evolution among the members of the acetylcholine receptor family [93]. SSD represents another important cholesterol interacting domain that consists of five transmembrane segments and is reported to be involved in cholesterol biosynthesis and homeostasis $[91,92]$. Yet another cholesterol binding site consisting of four amino acids was identified in a crystal structure of the $\beta_{2}$-adrenergic receptor and termed as CCM [29] (see Figure 3(b)). The location of CCM in the crystal structure of the $\beta_{2}$-adrenergic receptor is between transmembrane helices I, II, III, and IV with two cholesterol molecules bound per receptor monomer (Figure 3(b)). Interestingly, a similar site was found in the serotonin $_{1 \mathrm{~A}}$ receptor and was shown to be conserved over natural evolution [61].

3.3. Sphingolipids and GPCR Function. Sphingolipids are essential components of cellular membranes and represent diverse and dynamic regulators of a variety of cellular processes. Sphingolipids are relatively abundant in the plasma membrane compared to intracellular membranes [95]. They are involved in the regulation of cell growth, differentiation, and neoplastic transformation via participation in cell-cell communication [96]. The distribution of sphingolipids in the cellular membrane appears to be heterogeneous, and it has been proposed that sphingolipids, along with cholesterol, localize in laterally segregated lipid domains (sometimes termed as "lipid rafts") [97-99]. Many of these domains are believed to be important for the maintenance of cell membrane structure and function, although analysis of the spatiotemporal resolution of these domains has proved to be challenging $[100,101]$. Recent evidence suggests that sphingolipids, along with cholesterol, play a crucial role in organization, dynamics, and function of GPCRs [102-107]. Importantly, we recently reported a putative sphingolipidbinding domain in the serotonin ${ }_{1 \mathrm{~A}}$ receptor which partially overlaps with CRAC domain in transmembrane domain II of the receptor [108].

\section{GPCR Oligomerization and Drug Discovery}

An emerging topic of research is oligomerization of GPCRs and the possible role of oligomerization in GPCR function and signaling [109-113]. Yet, studying oligomerization of GPCRs has proved to be challenging. The potential implications of such oligomerization are far reaching, particularly in the context of GPCRs as major drug targets [114-116]. GPCR oligomerization facilitates an increased crosstalk between receptors via homo- and/or heterodimers as well as higherorder oligomers $[112,115,117]$. Interestingly, membrane lipids have recently been implicated in the modulation of GPCR oligomerization [116-118].

GPCR oligomerization has been widely studied utilizing fluorescence resonance energy transfer (FRET) methods such as hetero-FRET in live cells [110]. It turns out, however, that hetero-FRET is often associated with a number of inherent complications, arising from the use of receptors conjugated to two different probes and the lack of control in their relative expression levels [119-121]. Hetero-FRET measurements are performed utilizing two different fluorophores with sufficient spectral overlap. In case of heterologously expressed proteins, the expression levels of the tagged proteins may vary (giving rise to artifactual bystander FRET [121]), making intensitybased hetero-FRET measurements difficult to interpret. These factors have limited the usefulness of hetero-FRET in studies of GPCR oligomerization. In contrast to hetero-FRET, homo-FRET represents a better approach. Homo-FRET is a simpler variant of energy transfer since it takes place between identical fluorophores and therefore requires only a single type of fluorophore. Homo-FRET depends on the inverse sixth power of separation between interacting fluorophores on the nanometre scale and is therefore sensitive to protein oligomerization. The excitation and emission spectra of fluorophores exhibiting homo-FRET should have considerable overlap. In addition, homo-FRET gets manifested by reduction in fluorescence anisotropy [122]. Another serious limitation of hetero-FRET measurements is the lack of ability to distinguish dimers from higher order oligomers. Fortunately, homo-FRET measurements can provide an estimate of higher order oligomerization [117, 123, 124].

The presence of constitutive oligomers of the serotonin $\mathrm{in}_{1 \mathrm{~A}}$ receptor in live cells was demonstrated utilizing photobleaching homo-FRET [117]. This was shown from the observed increase in fluorescence anisotropy upon progressive photobleaching of the serotonin $_{1 \mathrm{~A}}$ receptor tagged to enhanced yellow fluorescent protein (EYFP). The fluorescently tagged serotonin $_{1 \mathrm{~A}}$ receptor has previously been shown to be essentially similar to the native receptor [125]. Analysis of the difference between the extrapolated and the predicted fluorescence anisotropy upon photobleaching revealed the presence of constitutive oligomers of the serotonin ${ }_{1 \mathrm{~A}}$ receptor in cells [117]. These results were supported by analysis of receptor oligomerization by time-resolved fluorescence anisotropy decay [118].

In a very recent work, it has been shown by MARTINI coarse-grain molecular dynamics simulations that the composition of the helical interface (i.e., helices at the interface) of 


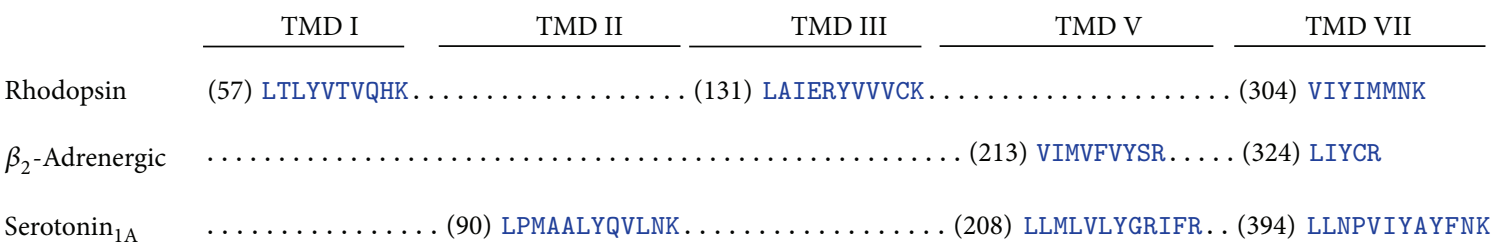

(a)

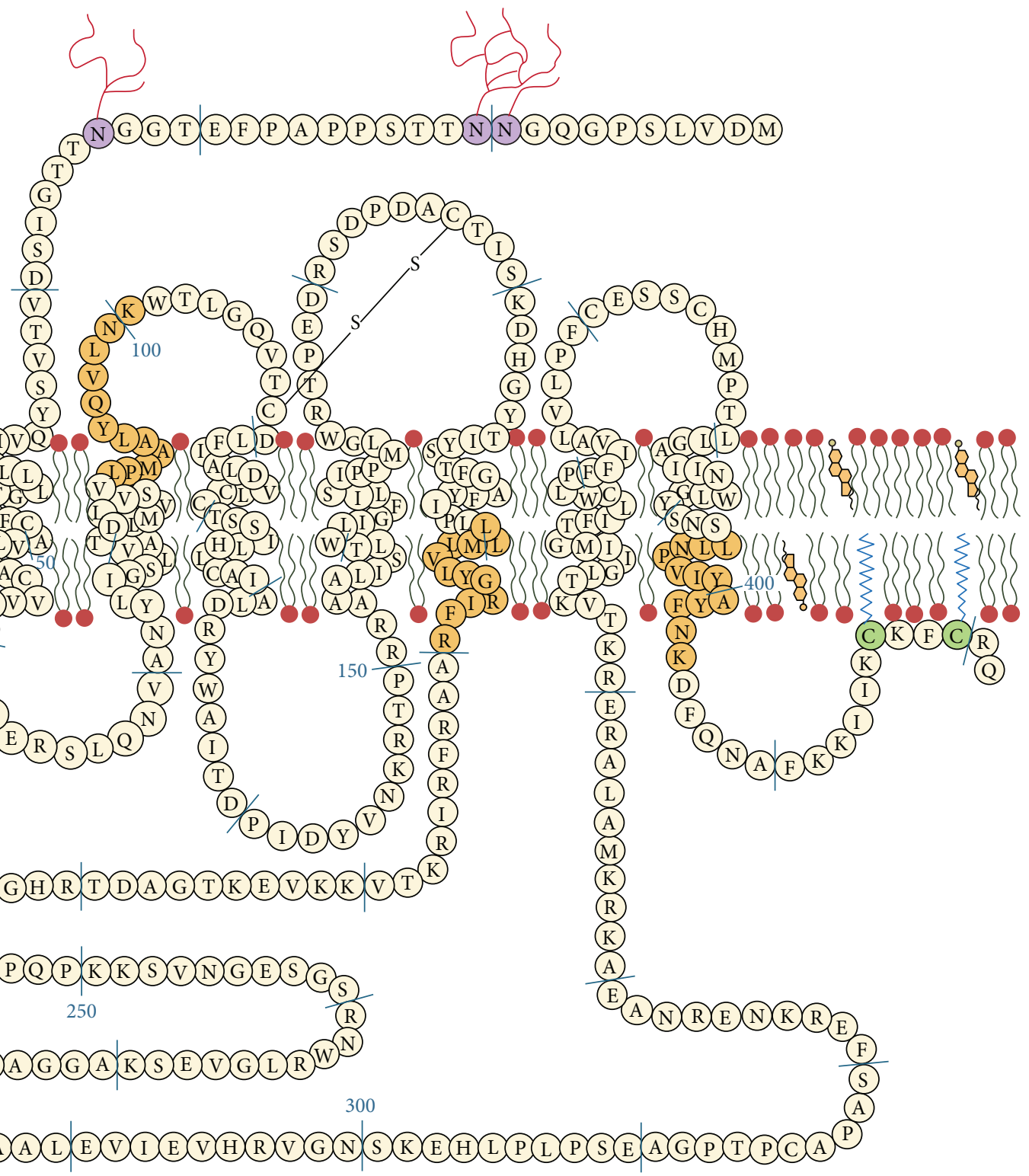

(b)

FIGURE 4: Putative cholesterol recognition/interaction amino acid consensus (CRAC) motifs in human GPCRs. (a) CRAC motifs in transmembrane domains (TMD) of representative GPCRs such as rhodopsin, $\beta_{2}$-adrenergic receptor, and serotonin a $_{1 \mathrm{~A}}$ receptor. The position of the starting amino acid residue in the respective CRAC sequence is denoted in parentheses. (b) A schematic representation of the human

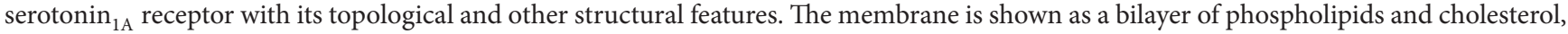
representative of typical eukaryotic membranes. The putative CRAC motifs are highlighted (in yellow) (adapted from [38]). Coarse-grain molecular dynamics simulations have validated high occupancy of cholesterol at some of the CRAC sites [39]. See text for other details. 


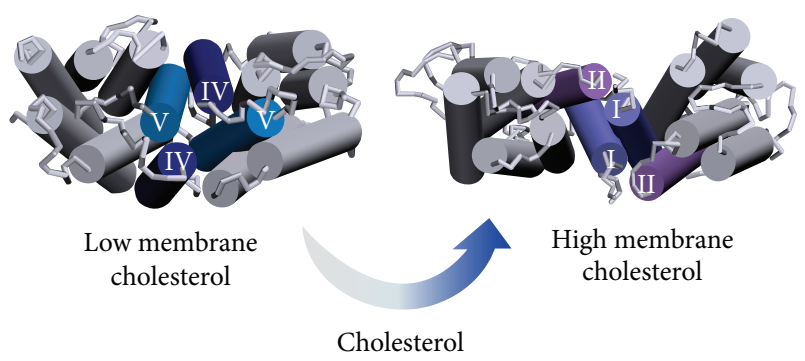

FIGURE 5: Membrane cholesterol modulates the dimer interface of the $\beta_{2}$-adrenergic receptor. Coarse-grain molecular dynamics simulations show that the receptor dimerization is modulated by membrane cholesterol content. With increasing membrane cholesterol, the transmembrane helices of the $\beta_{2}$-adrenergic receptor that comprise the dimer interface, display variation. At low membrane cholesterol, the dimer interface is mainly composed of transmembrane helices IV and V. Interestingly, at high membrane cholesterol, the dimer interface consists of transmembrane helices I and II. These results imply that dimer plasticity, induced by varying membrane cholesterol content, is potentially useful in drug development. Data obtained from [40]. See text for more details.

the dimer for the $\beta_{2}$-adrenergic receptor could vary depending on membrane cholesterol content [40] (see Figure 5). At low membrane cholesterol content, the dimer interface is mainly composed of transmembrane helices IV and V of each monomer. At high membrane cholesterol, the dimer interface consists of transmembrane helices I and II from each monomer. A progressive change in the dimer interface is observed with increasing concentration of membrane cholesterol. These results demonstrate dimer plasticity induced by varying cholesterol content in the membrane and have potential implications in drug development. Interestingly, cellular cholesterol is known to be developmentally regulated and its content increases with aging $[126,127]$. This could imply that the organization of GPCR oligomers could be age-dependent. The efficacy of a specific drug, designed to target a GPCR dimeric interface, could therefore change with the process of aging.

\section{Conclusion and the Road Ahead}

GPCRs represent one of the evolutionarily conserved families of membrane receptors dating back more than a billion years [6]. In contemporary biology, GPCRs occupy a unique crossroad. GPCR structural analysis allows a deeper understanding of membrane protein folding leading to cell signaling. On the other hand, they are the major players of intercellular communication throughout the human body and thereby they control diverse physiological functions ranging from blood pressure, neuronal activity to reproduction. Although GPCRs represent the most predominant therapeutic targets, a large fraction of the GPCR receptorome remains unexplored from both basic biology and drug discovery perspectives [128]. It has been estimated that $\sim 150$ GPCRs are orphan receptors whose endogenous ligands and functions are not yet known. These orphan receptors would be very useful and could act as targets for future drug discovery. In that sense,
GPCRs represent a meeting ground where biology meets medicine. With increasing evidence of specific lipid binding sites in GPCRs $[38,108]$, mutational analysis of the amino acid residues involved in such interactions, followed by functional and organizational analyses of the receptor, is likely to provide a better understanding on specific lipid dependence of the receptor function. Such progress in deciphering molecular details of the nature of this interaction in the membrane, coupled with emerging structural details of active receptors from X-ray crystallography and NMR, would lead to better insight into our overall understanding of GPCR function in health and disease.

\section{Abbreviations \\ CCM: Cholesterol consensus motif \\ CRAC: Cholesterol recognition/interaction amino acid consensus \\ FRET: Fluorescence resonance energy transfer \\ GPCR: G protein-coupled receptor \\ $\mathrm{M} \beta \mathrm{CD}$ : Methyl- $\beta$-cyclodextrin \\ SSD: Sterol-sensing domain.}

\section{Conflict of Interests}

The author declares that there is no conflict of interests regarding the publication of this paper.

\section{Acknowledgments}

Work in the laboratory was supported by the Council of Scientific and Industrial Research and Department of Biotechnology, Government of India. Support from J.C. Bose Fellowship (Department of Science and Technology, Government of India) is gratefully acknowledged. Some of the work described in this paper was carried out by former and present members of the group and the collaborator Dr. Durba Sengupta. Their contributions are gratefully acknowledged. Deep appreciation and special thanks are due to Md. Jafurulla for help during the preparation of the paper. The author thanks G. Aditya Kumar and Md. Jafurulla for help in making figures and also thanks members of the research group for critically reading the paper.

\section{References}

[1] K. L. Pierce, R. T. Premont, and R. J. Lefkowitz, "Seventransmembrane receptors," Nature Reviews Molecular Cell Biology, vol. 3, no. 9, pp. 639-650, 2002.

[2] D. M. Perez, "The evolutionarily triumphant G-protein-coupled receptor," Molecular Pharmacology, vol. 63, no. 6, pp. 1202-1205, 2003.

[3] D. M. Rosenbaum, S. G. F. Rasmussen, and B. K. Kobilka, "The structure and function of G-protein-coupled receptors," Nature, vol. 459, no. 7245, pp. 356-363, 2009.

[4] A. J. Venkatakrishnan, X. Deupi, G. Lebon, C. G. Tate, G. F. Schertler, and M. Madan Babu, "Molecular signatures of Gprotein-coupled receptors," Nature, vol. 494, no. 7436, pp. 185$194,2013$. 
[5] Y. Zhang, M. E. Devries, and J. Skolnick, "Structure modeling of all identified G protein-coupled receptors in the human genome," PLoS Computational Biology, vol. 2, no. 2, article e13, 2006.

[6] T. Schöneberg, M. Hofreiter, A. Schulz, and H. Römpler, "Learning from the past: evolution of GPCR functions," Trends in Pharmacological Sciences, vol. 28, no. 3, pp. 117-121, 2007.

[7] R. Fredriksson, M. C. Lagerström, L.-G. Lundin, and H. B. Schiöth, "The G-protein-coupled receptors in the human genome form five main families. Phylogenetic analysis, paralogon groups, and fingerprints," Molecular Pharmacology, vol. 63, no. 6, pp. 1256-1272, 2003.

[8] A. Krishnan, M. S. Almén, R. Fredriksson, and H. B. Schiöth, "The origin of GPCRs: identification of mammalian like Rhodopsin, Adhesion, Glutamate and Frizzled GPCRs in fungi," PLoS ONE, vol. 7, no. 1, Article ID e29817, 2012.

[9] U. Gether, "Uncovering molecular mechanisms involved in activation of G protein-coupled receptors," Endocrine Reviews, vol. 21, no. 1, pp. 90-113, 2000.

[10] C. Ellis, “The state of GPCR research in 2004," Nature Reviews. Drug Discovery, vol. 3, no. 7, pp. 577-626, 2004.

[11] E. Jacoby, R. Bouhelal, M. Gerspacher, and K. Seuwen, "The 7TM G-protein-coupled receptor target family," ChemMedChem, vol. 1, no. 8, pp. 760-782, 2006.

[12] P. A. Insel, C.-M. Tang, I. Hahntow, and M. C. Michel, "Impact of GPCRs in clinical medicine: monogenic diseases, genetic variants and drug targets," Biochimica et Biophysica Acta, vol. 1768, no. 4, pp. 994-1005, 2007.

[13] R. Heilker, M. Wolff, C. S. Tautermann, and M. Bieler, "Gprotein-coupled receptor-focused drug discovery using a target class platform approach," Drug Discovery Today, vol. 14, no. 5-6, pp. 231-240, 2009.

[14] S. Schlyer and R. Horuk, "I want a new drug: G-protein-coupled receptors in drug development," Drug Discovery Today, vol. 11, no. 11-12, pp. 481-493, 2006.

[15] W. Thomsen, J. Frazer, and D. Unett, "Functional assays for screening GPCR targets," Current Opinion in Biotechnology, vol. 16, no. 6, pp. 655-665, 2005.

[16] S. H. S. Lin and O. Civelli, "Orphan G protein-coupled receptors: targets for new therapeutic interventions," Annals of Medicine, vol. 36, no. 3, pp. 204-214, 2004.

[17] B. L. Roth and F. H. Marshall, "NOBEL 2012 chemistry: studies of a ubiquitous receptor family," Nature, vol. 491, article 57, no. 7427, 2012.

[18] L. Anson, "Membrane protein biophysics," Nature, vol. 459, no. 7245, article 343, 2009.

[19] J. Deisenhofer, O. Epp, and K. Miki, "Structure of the protein subunits in the photosynthetic reaction centre of Rhodopseudomonas viridis at $3 \AA$ resolution," Nature, vol. 318, no. 6047, pp. 618-624, 1985.

[20] X. Deupi and B. K. Kobilka, "Energy landscapes as a tool to integrate GPCR structure, dynamics, and function," Physiology, vol. 25, no. 5, pp. 293-303, 2010.

[21] M. Audet and M. Bouvier, "Insights into signaling from the $\beta_{2}$ adrenergic receptor structure," Nature Chemical Biology, vol. 4 , no. 7, pp. 397-403, 2008.

[22] Z. Yao and B. Kobilka, "Using synthetic lipids to stabilize purified $\beta_{2}$ adrenoceptor in detergent micelles," Analytical Biochemistry, vol. 343, no. 2, pp. 344-346, 2005.

[23] Y. D. Paila, S. Tiwari, D. Sengupta, and A. Chattopadhyay, "Molecular modeling of the human serotonin1A receptor: role of membrane cholesterol in ligand binding of the receptor," Molecular BioSystems, vol. 7, no. 1, pp. 224-234, 2011.

[24] R. Saxena and A. Chattopadhyay, "Membrane cholesterol stabilizes the human serotonin ${ }_{1 A}$ receptor," Biochimica et Biophysica Acta, vol. 1818, no. 12, pp. 2936-2942, 2012.

[25] R. Nygaard, Y. Zou, R. O. Dror et al., "The dynamic process of $\beta_{2}$-adrenergic receptor activation," Cell, vol. 152, no. 3, pp. 532$542,2013$.

[26] P. Schmidt, L. Thomas, P. Müller, H. A. Scheidt, and D. Huster, "The G-protein-coupled neuropeptide y receptor type 2 is highly dynamic in lipid membranes as revealed by solid-state NMR spectroscopy," Chemistry, vol. 20, no. 17, pp. 4986-4992, 2014.

[27] D. F. Hansen, P. Vallurupalli, and L. E. Kay, "Using relaxation dispersion NMR spectroscopy to determine structures of excited, invisible protein states," Journal of Biomolecular NMR, vol. 41, no. 3, pp. 113-120, 2008.

[28] V. Cherezov, D. M. Rosenbaum, M. A. Hanson et al., "Highresolution crystal structure of an engineered human $\beta_{2}$ adrenergic G protein-coupled receptor," Science, vol. 318, no. 5854, pp. 1258-1265, 2007.

[29] M. A. Hanson, V. Cherezov, M. T. Griffith et al., "A specific cholesterol binding site is established by the $2.8 \AA$ structure of the human $\beta_{2}$-adrenergic receptor," Structure, vol. 16, no. 6, pp. 897-905, 2008.

[30] P. W. Day, S. G. F. Rasmussen, C. Parnot et al., "A monoclonal antibody for $\mathrm{G}$ protein-coupled receptor crystallography," Nature Methods, vol. 4, no. 11, pp. 927-929, 2007.

[31] D. M. Rosenbaum, V. Cherezov, M. A. Hanson et al., "GPCR engineering yields high-resolution structural insights into $\beta_{2}$ adrenergic receptor function," Science, vol. 318, no. 5854, pp. 1266-1273, 2007.

[32] S. G. F. Rasmussen, B. T. DeVree, Y. Zou et al., "Crystal structure of the $\beta_{2}$ adrenergic receptor-Gs protein complex," Nature, vol. 477, no. 7366, pp. 549-557, 2011.

[33] V. Katritch, V. Cherezov, and R. C. Stevens, "Structure-function of the G protein-coupled receptor superfamily," Annual Review of Pharmacology and Toxicology, vol. 53, pp. 531-556, 2013.

[34] S. H. Park, B. B. Das, F. Casagrande et al., "Structure of the chemokine receptor CXCR1 in phospholipid bilayers," Nature, vol. 491, no. 7426, pp. 779-783, 2012.

[35] M. Jafurulla, B. D. Rao, S. Sreedevi, J. M. Ruysschaert, D. F. Covey, and A. Chattopadhyay, "Stereospecific requirement of cholesterol in the function of the serotonin1A receptor," Biochimica et Biophysica Acta, vol. 1838, no. 1, pp. 158-163, 2014.

[36] M. Jafurulla and A. Chattopadhyay, "Membrane lipids in the function of serotonin and adrenergic receptors," Current Medicinal Chemistry, vol. 20, no. 1, pp. 47-55, 2013.

[37] H. Wu, C. Wang, K. J. Gregory et al., "Structure of a class C GPCR metabotropic glutamate receptor 1 bound to an allosteric modulator," Science, vol. 344, no. 6179, pp. 58-64, 2014.

[38] M. Jafurulla, S. Tiwari, and A. Chattopadhyay, "Identification of cholesterol recognition amino acid consensus (CRAC) motif in G-protein coupled receptors," Biochemical and Biophysical Research Communications, vol. 404, no. 1, pp. 569-573, 2011.

[39] D. Sengupta and A. Chattopadhyay, "Identification of cholesterol binding sites in the serotonin ${ }_{1 A}$ receptor," Journal of Physical Chemistry B, vol. 116, no. 43, pp. 12991-12996, 2012.

[40] X. Prasanna, A. Chattopadhyay, and D. Sengupta, "Cholesterol modulates the dimer interface of the $\beta_{2}$ - adrenergic receptor via cholesterol occupancy sites," Biophysical Journal, vol. 106, no. 6, pp. 1290-1300, 2014. 
[41] K. Burger, G. Gimpl, and F. Fahrenholz, "Regulation of receptor function by cholesterol," Cellular and Molecular Life Sciences, vol. 57, no. 11, pp. 1577-1592, 2000.

[42] T. J. Pucadyil and A. Chattopadhyay, "Role of cholesterol in the function and organization of G-protein coupled receptors," Progress in Lipid Research, vol. 45, no. 4, pp. 295-333, 2006.

[43] Y. D. Paila and A. Chattopadhyay, "Membrane cholesterol in the function and organization of G-protein coupled receptors," SubCellular Biochemistry, vol. 51, pp. 439-466, 2010.

[44] J. Oates and A. Watts, "Uncovering the intimate relationship between lipids, cholesterol and GPCR activation," Current Opinion in Structural Biology, vol. 21, no. 6, pp. 802-807, 2011.

[45] S. Inagaki, R. Ghirlando, J. F. White, J. Gvozdenovic-Jeremic, J. K. Northup, and R. Grisshammer, "Modulation of the interaction between neurotensin receptor NTS1 and Gq protein by lipid," Journal of Molecular Biology, vol. 417, no. 1-2, pp. 95-111, 2012.

[46] R. Alemany, J. S. Perona, J. M. Sánchez-Dominguez et al., "G protein-coupled receptor systems and their lipid environment in health disorders during aging," Biochimica et Biophysica Acta-Biomembranes, vol. 1768, no. 4, pp. 964-975, 2007.

[47] J. Kirilovsky and M. Schramm, "Delipidation of a $\beta$-adrenergic receptor preparation and reconstitution by specific lipids," The Journal of Biological Chemistry, vol. 258, no. 11, pp. 6841-6849, 1983.

[48] K. Simons and E. Ikonen, "How cells handle cholesterol," Science, vol. 290, no. 5497, pp. 1721-1726, 2000.

[49] O. G. Mouritsen and M. J. Zuckermann, "What's so special about cholesterol?" Lipids, vol. 39, no. 11, pp. 1101-1113, 2004.

[50] X. Xu and E. London, "The effect of sterol structure on membrane lipid domains reveals how cholesterol can induce lipid domain formation," Biochemistry, vol. 39, no. 5, pp. 843849, 2000.

[51] S. Mukherjee and F. R. Maxfield, "Membrane domains," Annual Review of Cell and Developmental Biology, vol. 20, pp. 839-866, 2004.

[52] D. Lingwood and K. Simons, "Lipid rafts as a membraneorganizing principle," Science, vol. 327, no. 5961, pp. 46-50, 2010.

[53] A. Chaudhuri and A. Chattopadhyay, "Transbilayer organization of membrane cholesterol at low concentrations: implications in health and disease," Biochimica et Biophysica Acta, vol. 1808, no. 1, pp. 19-25, 2011.

[54] K. Simons and G. van Meer, "Lipid sorting in epithelial cells," Biochemistry, vol. 27, no. 17, pp. 6197-6202, 1988.

[55] K. Simons and D. Toomre, "Lipid rafts and signal transduction," Nature Reviews Molecular Cell Biology, vol. 1, no. 1, pp. 31-39, 2000.

[56] T. J. Pucadyil and A. Chattopadhyay, "Cholesterol: a potential therapeutic target in Leishmania infection?" Trends in Parasitology, vol. 23, no. 2, pp. 49-53, 2007.

[57] A. Chattopadhyay and M. Jafurulla, "Role of membrane cholesterol in leishmanial infection," Advances in Experimental Medicine and Biology, vol. 749, pp. 201-213, 2012.

[58] S. Roy, G. A. Kumar, M. Jafurulla, C. Mandal, and A. Chattopadhyay, "Integrity of the actin cytoskeleton of host macrophages is essential for Leishmania donovani infection," Biochimica et Biophysica Acta, vol. 1838, no. 8, pp. 2011-2018, 2014.

[59] Y. D. Paila and A. Chattopadhyay, "The function of G-protein coupled receptors and membrane cholesterol: specific or general interaction?” Glycoconjugate Journal, vol. 26, no. 6, pp. 711$720,2009$.
[60] A. G. Lee, "Biological membranes: the importance of molecular detail," Trends in Biochemical Sciences, vol. 36, no. 9, pp. 493500, 2011.

[61] Y. D. Paila, S. Tiwari, and A. Chattopadhyay, "Are specific nonannular cholesterol binding sites present in G-protein coupled receptors?" Biochimica et Biophysica Acta, vol. 1788, no. 2, pp. 295-302, 2009.

[62] A. C. Simmonds, J. M. East, O. T. Jones, E. K. Rooney, J. McWhirter, and A. G. Lee, "Annular and non-annular binding sites on the $\left(\mathrm{Ca}^{2+}+\mathrm{Mg}^{2+}\right)$-ATPase," Biochimica et Biophysica Acta: Biomembranes, vol. 693, no. 2, pp. 398-406, 1982.

[63] O. T. Jones and M. G. McNamee, "Annular and nonannular binding sites for cholesterol associated with the nicotinic acetylcholine receptor," Biochemistry, vol. 27, no. 7, pp. 2364-2374, 1988.

[64] A. G. Lee, "Lipid-protein interactions in biological membranes: a structural perspective," Biochimica et Biophysica Acta, vol. 1612, no. 1, pp. 1-40, 2003.

[65] A. G. Lee, J. M. East, O. T. Jones, J. McWhirter, E. K. Rooney, and A. C. Simmonds, "Interaction of fatty acids with the calcium-magnesium ion dependent adenosinetriphosphatase from sarcoplasmic reticulum," Biochemistry, vol. 21, no. 25, pp. 6441-6446, 1982.

[66] T. J. Pucadyil and A. Chattopadhyay, "Cholesterol modulates ligand binding and G-protein coupling to serotonin1A receptors from bovine hippocampus," Biochimica et Biophysica ActaBiomembranes, vol. 1663, no. 1-2, pp. 188-200, 2004.

[67] T. J. Pucadyil, S. Shrivastava, and A. Chattopadhyay, "The sterol-binding antibiotic nystatin differentially modulates ligand binding of the bovine hippocampal serotonin ${ }_{1 A}$ receptor," Biochemical and Biophysical Research Communications, vol. 320, no. 2, pp. 557-562, 2004.

[68] T. J. Pucadyil and A. Chattopadhyay, "Cholesterol modulates the antagonist-binding function of hippocampal serotonin ${ }_{1 A}$ receptors," Biochimica et Biophysica Acta, vol. 1714, no. 1, pp. 3542, 2005.

[69] T. J. Pucadyil, S. Shrivastava, and A. Chattopadhyay, "Membrane cholesterol oxidation inhibits ligand binding function of hippocampal serotonin $n_{1 A}$ receptors," Biochemical and Biophysical Research Communications, vol. 331, no. 2, pp. 422-427, 2005.

[70] Y. D. Paila, T. J. Pucadyil, and A. Chattopadhyay, "The cholesterol-complexing agent digitonin modulates ligand binding of the bovine hippocampal serotonin ${ }_{1 A}$ receptor," Molecular Membrane Biology, vol. 22, no. 3, pp. 241-249, 2005.

[71] Y. D. Paila, M. R. V. S. Murty, M. Vairamani, and A. Chattopadhyay, "Signaling by the human serotonin1A receptor is impaired in cellular model of Smith-Lemli-Opitz Syndrome," Biochimica et Biophysica Acta, vol. 1778, no. 6, pp. 1508-1516, 2008.

[72] S. Shrivastava, T. J. Pucadyil, Y. D. Paila, S. Ganguly, and A. Chattopadhyay, "Chronic cholesterol depletion using statin impairs the function and dynamics of human serotonin ${ }_{1 A}$ receptors," Biochemistry, vol. 49, no. 26, pp. 5426-5435, 2010.

[73] Y. D. Paila, E. Jindal, S. K. Goswami, and A. Chattopadhyay, "Cholesterol depletion enhances adrenergic signaling in cardiac myocytes," Biochimica et Biophysica Acta-Biomembranes, vol. 1808, no. 1, pp. 461-465, 2011.

[74] M. Zocher, C. Zhang, S. G. F. Rasmussen, B. K. Kobilka, and D. J. Müller, "Cholesterol increases kinetic, energetic,and mechanical stability of the human $\beta_{2}$-adrenergic receptor," Proceedings of the National Academy of Sciences of the United States of America, vol. 109, no. 50, pp. E3463-E3472, 2012. 
[75] T. J. Pucadyil, S. Kalipatnapu, and A. Chattopadhyay, "The serotonin1A receptor: a representative member of the serotonin receptor family," Cellular and Molecular Neurobiology, vol. 25, no. 3-4, pp. 553-580, 2005.

[76] C. P. Müller, R. J. Carey, J. P. Huston, and M. A. de Souza Silva, "Serotonin and psychostimulant addiction: focus on $5-\mathrm{HT}_{1 A^{-}}$ receptors," Progress in Neurobiology, vol. 81, no. 3, pp. 133-178, 2007.

[77] S. Kalipatnapu and A. Chattopadhyay, "Membrane organization and function of the serotonin1A receptor," Cellular and Molecular Neurobiology, vol. 27, no. 8, pp. 1097-1116, 2007.

[78] P. Blier and N. M. Ward, "Is there a role for $5-\mathrm{HT}_{1 A}$ agonists in the treatment of depression?" Biological Psychiatry, vol. 53, no. 3, pp. 193-203, 2003.

[79] G. Griebel, "5-HT(1A) receptor blockers as potential drug candidates for the treatment of anxiety disorders," Drug News and Perspectives, vol. 12, no. 8, pp. 484-490, 1999.

[80] P. Celada, A. Bortolozzi, and F. Artigas, "Serotonin 5- $\mathrm{HT}_{1 \mathrm{~A}}$ receptors as targets for agents to treat psychiatric disorders: rationale and current status of research," CNS Drugs, vol. 27, no. 9, pp. 703-716, 2013.

[81] P. Singh, Y. D. Paila, and A. Chattopadhyay, "Differential effects of cholesterol and 7-dehydrocholesterol on the ligand binding activity of the hippocampal serotonin ${ }_{1 A}$ receptor: implications in SLOS," Biochemical and Biophysical Research Communications, vol. 358, no. 2, pp. 495-499, 2007.

[82] A. Chattopadhyay, Y. D. Paila, M. Jafurulla et al., "Differential effects of cholesterol and 7-dehydrocholesterol on ligand binding of solubilized hippocampal serotonin1A receptors: implications in SLOS," Biochemical and Biophysical Research Communications, vol. 363, no. 3, pp. 800-805, 2007.

[83] P. Singh, R. Saxena, Y. D. Paila, M. Jafurulla, and A. Chattopadhyay, "Differential effects of cholesterol and desmosterol on the ligand binding function of the hippocampal serotonin ${ }_{1 A}$ receptor: implications in desmosterolosis," Biochimica et Biophysica Acta, vol. 1788, no. 10, pp. 2169-2173, 2009.

[84] R. Prasad, P. Singh, and A. Chattopadhyay, "Effect of capsaicin on ligand binding activity of the hippocampal serotonin $n_{1 A}$ receptor," Glycoconjugate Journal, vol. 26, no. 6, pp. 733-738, 2009.

[85] J. J. Ruprecht, T. Mielke, R. Vogel, C. Villa, and G. F. X. Schertler, "Electron crystallography reveals the structure of metarhodopsin I," The EMBO Journal, vol. 23, no. 18, pp. 36093620, 2004.

[86] T. Warne, R. Moukhametzianov, J. G. Baker et al., "The structural basis for agonist and partial agonist action on a $\beta 1-$ adrenergic receptor," Nature, vol. 469, no. 7329, pp. 241-244, 2011.

[87] W. Liu, E. Chun, A. A. Thompson et al., "Structural basis for allosteric regulation of GPCRS by sodium ions," Science, vol. 337, no. 6091, pp. 232-236, 2012.

[88] G. Gimpl, "Cholesterol-protein interaction: methods and cholesterol reporter molecules," Sub-cellular biochemistry, vol. 51, pp. 1-45, 2010.

[89] H. Li and V. Papadopoulos, "Peripheral-type benzodiazepine receptor function in cholesterol transport. Identification of a putative cholesterol recognition/interaction amino acid sequence and consensus pattern," Endocrinology, vol. 139, no. 12, pp. 4991-4997, 1998.

[90] R. M. Epand, "Cholesterol and the interaction of proteins with membrane domains," Progress in Lipid Research, vol. 45, no. 4, pp. 279-294, 2006.
[91] M. S. Brown and J. L. Goldstein, "A proteolytic pathway that controls the cholesterol content of membranes, cells, and blood," Proceedings of the National Academy of Sciences of the United States of America, vol. 96, no. 20, pp. 11041-11048, 1999.

[92] P. E. Kuwabara and M. Labouesse, "The sterol-sensing domain: multiple families, a unique role?" Trends in Genetics, vol. 18, no. 4, pp. 193-201, 2002.

[93] C. J. Baier, J. Fantini, and F. J. Barrantes, "Disclosure of cholesterol recognition motifs in transmembrane domains of the human nicotinic acetylcholine receptor," Scientific Reports, vol. 1, article 69, 2011.

[94] S. Oddi, E. Dainese, F. Fezza et al., "Functional characterization of putative cholesterol binding sequence (CRAC) in human type-1 cannabinoid receptor," Journal of Neurochemistry, vol. 116, no. 5, pp. 858-865, 2011.

[95] J. C. M. Holthuis, T. Pomorski, R. J. Raggers, H. Sprong, and G. van Meer, "The organizing potential of sphingolipids in intracellular membrane transport," Physiological Reviews, vol. 81, no. 4, pp. 1689-1723, 2001.

[96] Y. A. Hannun and L. M. Obeid, "Principles of bioactive lipid signalling: lessons from sphingolipids," Nature Reviews Molecular Cell Biology, vol. 9, no. 2, pp. 139-150, 2008.

[97] R. E. Brown, "Sphingolipid organization in biomembranes: what physical studies of model membranes reveal," Journal of Cell Science, vol. 111, no. 1, pp. 1-9, 1998.

[98] B. Ramstedt and J. P. Slotte, "Sphingolipids and the formation of sterol-enriched ordered membrane domains," Biochimica et Biophysica Acta: Biomembranes, vol. 1758, no. 12, pp. 1945-1956, 2006.

[99] M. Masserini and D. Ravasi, "Role of sphingolipids in the biogenesis of membrane domains," Biochimica et Biophysica Acta, vol. 1532, no. 3, pp. 149-161, 2001.

[100] K. Jacobson, O. G. Mouritsen, and R. G. W. Anderson, "Lipid rafts: at a crossroad between cell biology and physics," Nature Cell Biology, vol. 9, no. 1, pp. 7-14, 2007.

[101] S. Ganguly and A. Chattopadhyay, "Cholesterol depletion mimics the effect of cytoskeletal destabilization on membrane dynamics of the serotonin ${ }_{1 A}$ receptor: a zFCS study," Biophysical Journal, vol. 99, no. 5, pp. 1397-1407, 2010.

[102] B. Sjögren and P. Svenningsson, "Depletion of the lipid raft constituents, sphingomyelin and ganglioside, decreases serotonin binding at human 5- $\mathrm{HT}_{7(a)}$ receptors in HeLa cells," Acta Physiologica, vol. 190, no. 1, pp. 47-53, 2007.

[103] M. Jafurulla, T. J. Pucadyil, and A. Chattopadhyay, "Effect of sphingomyelinase treatment on ligand binding activity of human serotonin ${ }_{1 A}$ receptors," Biochimica et Biophysica Acta, vol. 1778, no. 10, pp. 2022-2025, 2008.

[104] Y. D. Paila, S. Ganguly, and A. Chattopadhyay, "Metabolic depletion of sphingolipids impairs ligand binding and signaling of human serotonin ${ }_{1 A}$ receptors," Biochemistry, vol. 49, no. 11, pp. 2389-2397, 2010.

[105] S. Ganguly, Y. D. Paila, and A. Chattopadhyay, "Metabolic depletion of sphingolipids enhances the mobility of the human

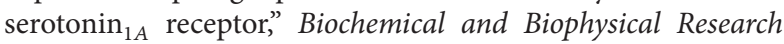
Communications, vol. 411, no. 1, pp. 180-184, 2011.

[106] P. Singh and A. Chattopadhyay, "Removal of sphingomyelin headgroup inhibits the ligand binding function of hippocampal

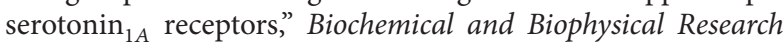
Communications, vol. 419, no. 2, pp. 321-325, 2012.

[107] P. Singh, Y. D. Paila, and A. Chattopadhyay, "Role of glycosphingolipids in the function of human serotonin1A receptors," Journal of Neurochemistry, vol. 123, no. 5, pp. 716-724, 2012. 
[108] A. Chattopadhyay, Y. D. Paila, S. Shrivastava, S. Tiwari, P. Singh, and J. Fantini, "Sphingolipid-binding domain in the serotonin ${ }_{1 A}$ receptor," Advances in Experimental Medicine and Biology, vol. 749, pp. 279-293, 2012.

[109] K. Shanti and A. Chattopadhyay, "A new paradigm in the functioning of G-protein-coupled receptors," Current Science, vol. 79, pp. 402-403, 2000.

[110] M. J. Lohse, "Dimerization in GPCR mobility and signaling," Current Opinion in Pharmacology, vol. 10, no. 1, pp. 53-58, 2010.

[111] K. Palczewski, "Oligomeric forms of G protein-coupled receptors (GPCRs)," Trends in Biochemical Sciences, vol. 35, no. 11, pp. 595-600, 2010.

[112] L. Albizu, M. Cottet, M. Kralikova et al., "Time-resolved FRET between GPCR ligands reveals oligomers in native tissues," Nature Chemical Biology, vol. 6, no. 8, pp. 587-594, 2010.

[113] G. Milligan, "The role of dimerisation in the cellular trafficking of G-protein-coupled receptors," Current Opinion in Pharmacology, vol. 10, no. 1, pp. 23-29, 2010.

[114] R. Panetta and M. T. Greenwood, "Physiological relevance of GPCR oligomerization and its impact on drug discovery," Drug Discovery Today, vol. 13, no. 23-24, pp. 1059-1066, 2008.

[115] J. González-Maeso, R. L. Ang, T. Yuen et al., "Identification of a serotonin/glutamate receptor complex implicated in psychosis," Nature, vol. 452, no. 7183, pp. 93-97, 2008.

[116] V. Casadó, A. Cortés, J. Mallol et al., “GPCR homomers and heteromers: a better choice as targets for drug development than GPCR monomers?" Pharmacology and Therapeutics, vol. 124, no. 2, pp. 248-257, 2009.

[117] S. Ganguly, A. H. A. Clayton, and A. Chattopadhyay, "Organization of higher-order oligomers of the serotonin ${ }_{1 A}$ receptor explored utilizing homo-FRET in live cells," Biophysical Journal, vol. 100, no. 2, pp. 361-368, 2011.

[118] Y. D. Paila, M. Kombrabail, G. Krishnamoorthy, and A. Chattopadhyay, "Oligomerization of the serotonin ${ }_{1 A}$ receptor in live cells: a time-resolved fluorescence anisotropy approach," The Journal of Physical Chemistry B, vol. 115, no. 39, pp. 11439-11447, 2011.

[119] J. R. James, M. I. Oliveira, A. M. Carmo, A. Iaboni, and S. J. Davis, "A rigorous experimental framework for detecting protein oligomerization using bioluminescence resonance energy transfer," Nature Methods, vol. 3, no. 12, pp. 1001-1006, 2006.

[120] B. H. Meyer, J.-M. Segura, K. L. Martinez et al., "FRET imaging reveals that functional neurokinin-1 receptors are monomeric and reside in membrane microdomains of live cells," Proceedings of the National Academy of Sciences of the United States of America, vol. 103, no. 7, pp. 2138-2143, 2006.

[121] A. H. A. Clayton and A. Chattopadhyay, "Taking care of bystander FRET in a crowded cell membrane environment," Biophysical Journal, vol. 106, no. 6, pp. 1227-1228, 2014.

[122] M. Tramier, T. Piolot, I. Gautier et al., "Homo-FRET versus hetero-FRET to probe homodimers in living cells," Methods in Enzymology, vol. 360, pp. 580-597, 2003.

[123] L. W. Runnels and S. F. Scarlata, "Theory and application of fluorescence homotransfer to melittin oligomerization," Biophysical Journal, vol. 69, no. 4, pp. 1569-1583, 1995.

[124] E. K. L. Yeow and A. H. A. Clayton, "Enumeration of oligomerization states of membrane proteins in living cells by homoFRET spectroscopy and microscopy: theory and application," Biophysical Journal, vol. 92, no. 9, pp. 3098-3104, 2007.

[125] T. J. Pucadyil, S. Kalipatnapu, K. G. Harikumar, N. Rangaraj, S. S. Karnik, and A. Chattopadhyay, "G-protein-dependent cell surface dynamics of the human serotonin ${ }_{1 A}$ receptor tagged to yellow fluorescent protein," Biochemistry, vol. 43, no. 50, pp. 15852-15862, 2004.

[126] M. Martin, C. G. Dotti, and M. D. Ledesma, "Brain cholesterol in normal and pathological aging," Biochimica et Biophysica Acta, vol. 1801, no. 8, pp. 934-944, 2010.

[127] A. M. Stranahan, R. G. Cutler, C. Button, R. Telljohann, and M. P. Mattson, "Diet-induced elevations in serum cholesterol are associated with alterations in hippocampal lipid metabolism and increased oxidative stress," Journal of Neurochemistry, vol. 118, no. 4, pp. 611-615, 2011.

[128] J. A. Allen and B. L. Roth, "Strategies to discover unexpected targets for drugs active at G protein-coupled receptors," Annual Review of Pharmacology and Toxicology, vol. 51, pp. 117-144, 2011. 

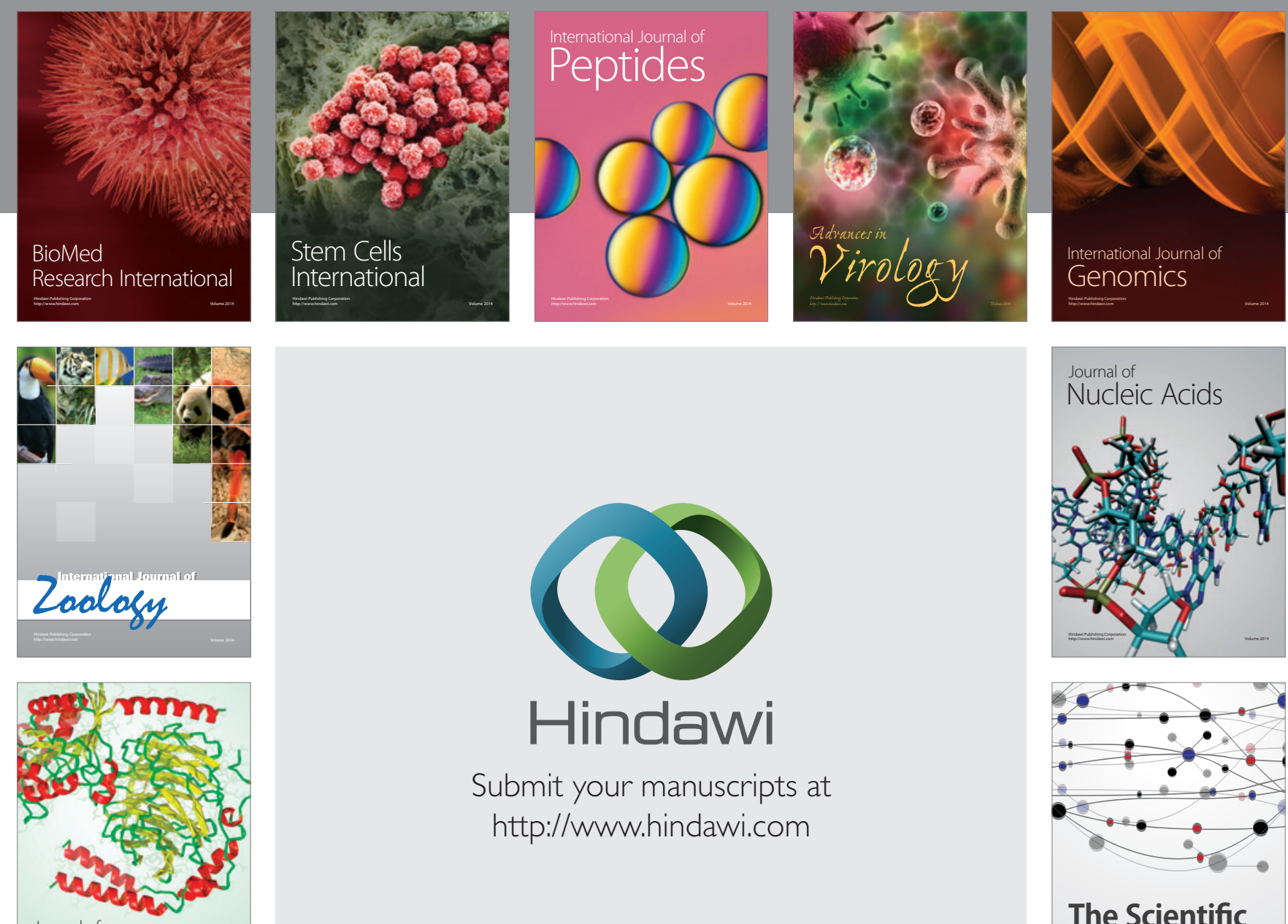

Submit your manuscripts at

http://www.hindawi.com

Journal of
Signal Transduction
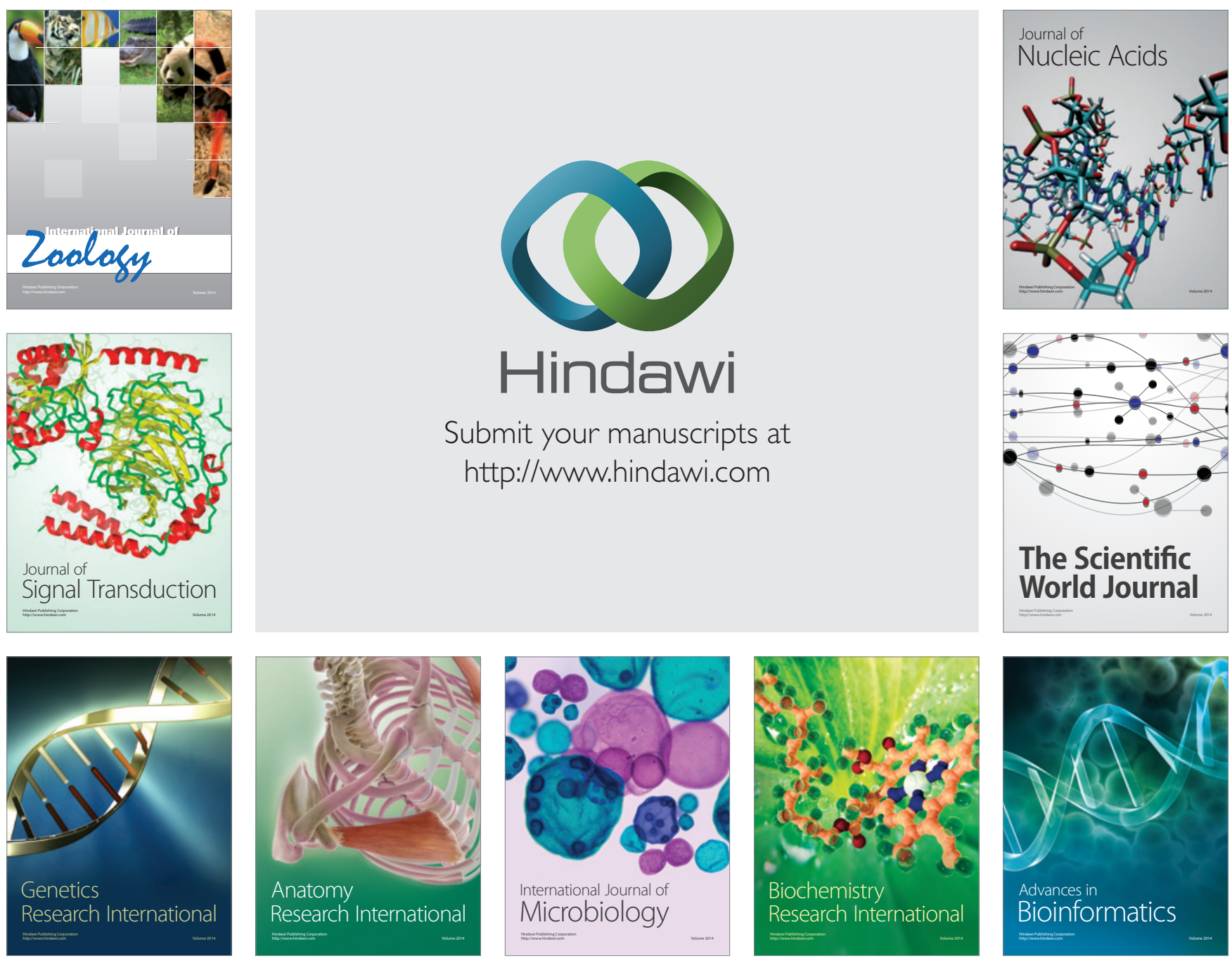

The Scientific World Journal
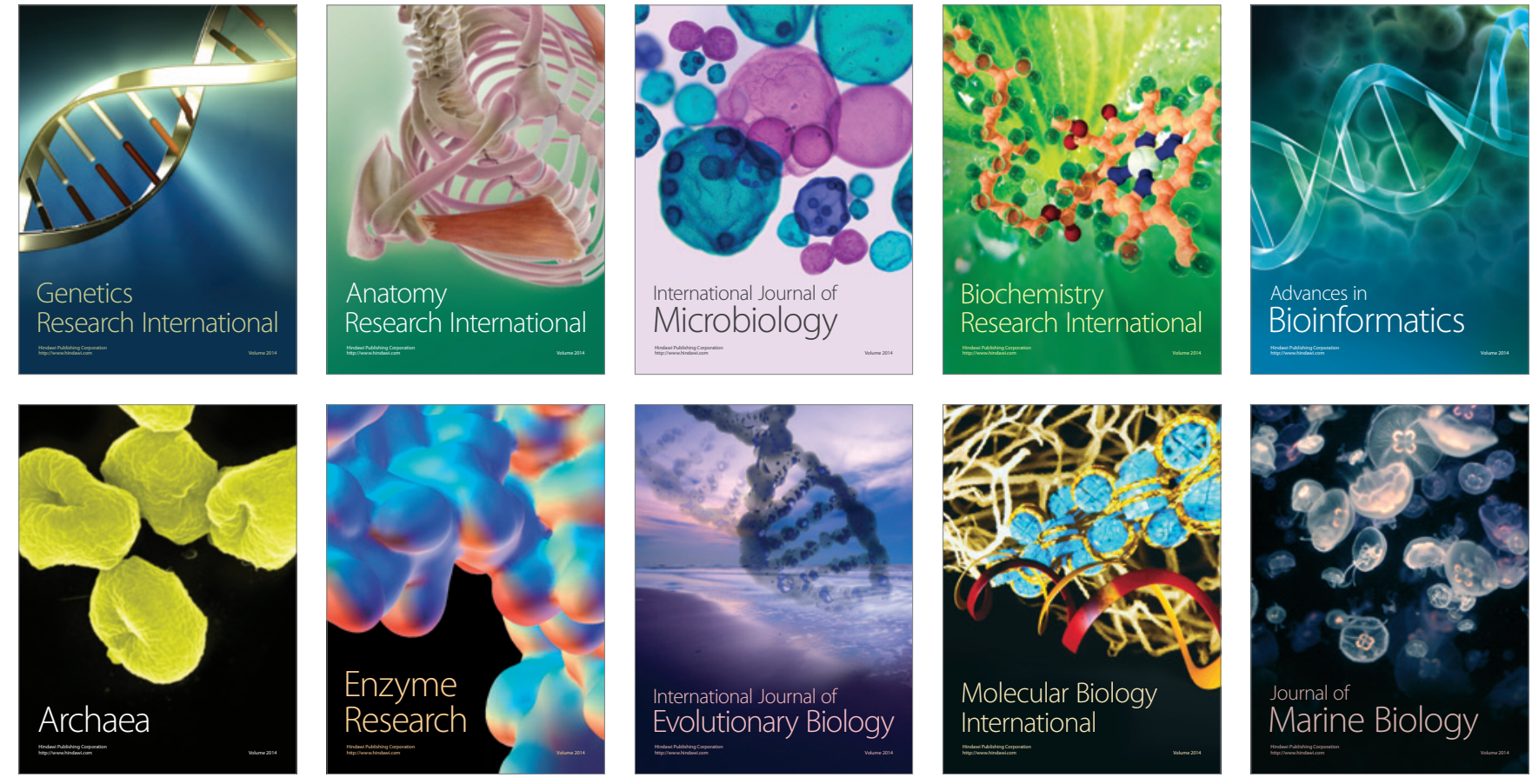